\title{
Considerações acerca da vivência dos indivíduos na era neoliberal a partir do pensamento de Martin Buber
}

\author{
Considerations about the experience of individuals in the neoliberal age from \\ Martin Buber's thought
}

\section{Suellen Lima de Brito*}

Resumo: O presente estudo visa analisar a obra Eu e Tu de Martin Buber (1878-1965), a obra apresenta os conceitos: Eu-Tu e o Eu-Isso como palavras-princípios. O Eu-Tu como uma relação dialógica, encontro entre dois parceiros mutualmente e o Eu-Isso como um relaçionamento monológico, de experiência, utilização ou uso. O mundo do Isso se invadir e orientar as formas dos homens relacionarem-se levam estes à perdição. Nesse sentido, o sistema econômico vigente, que rege as normas de comportamento dos indivíduos em sociedade, corrobora para que o mundo do Isso preconizado por Buber torna-se mais presente na vida dos indivíduos, pois a vivência destes na era neoliberal está prejudicada em nome do capital que mantém seu sistema à custa desta vivência dos sujeitos, onde os explora e instiga a competição em detrimento da solidariedade e companheirismo, competição legitimada que aprofunda o individualismo contemporâneo, onde os indivíduos sucumbem tragicamente em seu interior.

Palavras-chaves: Eu-Tu; Eu-Isso; Existência fragilizada; Neoliberalismo

Abstract: The present study aims to analyze the work I and Thou by Martin Buber (18781965), the work presents the concepts: Me-You and I-That as principle words. The I-You as a dialogical relationship, meeting between two partners mutually and the I-It as a monological relationship, of experience, use or use. The world of That if you invade and guide the ways of men to relate, they lead to perdition. In this sense, the current economic system, which governs the norms of behavior of individuals in society, corroborates that the world of That advocated by Buber becomes more present in the lives of individuals, as their experience in the neoliberal era is impaired in the name the capital that maintains its system at the expense of this experience of the subjects, where it explores and instigates competition to the detriment of solidarity and companionship, a legitimate competition that deepens contemporary individualism, where individuals succumb tragically within.

Keywords: Me-You; I-That; Fragile existence; Neoliberalism

\section{Introdução}

Martin Buber (1878-1965) foi um filósofo austríaco naturalizado israelita, que nasceu na cidade de Viena, e desde seus primeiros anos de vida, passou por diversas experiências que influenciariam a sua personalidade e mentalidade que posteriormente deram "luz" a sua filosofia. Devido à influência de seu avô Salomão Buber, ele interessa-se pelo hassídismo e pela cultura judaica, que influenciam sua filosofia do diálogo. Suas obras transpiram alteridade e poesia, respeito ao outro e responsabilidade, sua base é a relação que extraiu de profundas vivências pessoais, seus estudos hassídicos lhe oportunou um profundo respeito ao homem e um olhar doce e cheio de esperança à humanidade. A existencialidade em Buber é, antes de tudo, dialógica, baseada na pronúncia do $T u$, reiterando o cunho de que o humanismo buberiano tem um caráter de resgate, um resgate dialógico que conduz à uma vida humanizante, e para isso, é necessário que ocorra a decisão para que essa mudança de perspectiva ocorra.

\footnotetext{
* Mestranda em Filosofia pela Universidade Federal do Pará, Belém, PA. E-mail: suellenlima hp@hotmail.com ORCID: https://orcid.org/o00o-0002-7654-4851
} 
A primazia do diálogo nasceu em Buber desde muito cedo e isso se materializou em sua obra Eu e Tu (1923), considerada a porta de entrada de seu pensamento, que se divide em três partes ${ }^{1}$, sendo as duas primeiras, dedicadas às conjecturas das relações $E u$-Tu e Eu-Isso. Sua filosofia e sua escrita não se preocupavam em estabelecer determinadas direções, assim como faziam os outros sistemas filosóficos, direções estas, metódicas e complicadas. De fato, Buber tinha como objetivo, tratar sobre problemas reais. Sua preocupação era o ser humano em si mesmo, o qual possui relações interpessoais e estava inserido na sociedade, enfrentando os percalços da vida social, política e economicamente ativa.

Para Martin Buber, o homem vive entre duas dualidades distintas entre si, que denominou como palavras-princípios, a saber: o Eu-Tu e o Eu-Isso. Estas palavras-princípios são um modo de existir proferidas pelo ser, é inerente à condição humana, e fundamenta nossa existência. O Eu-Tu como uma relação dialógica, um encontro atual que ocorre entre dois parceiros de forma mútua e autêntica e o Eu-Isso como um relacionamento monológico, com fins objetificantes ao outro, baseados em experiência, em utilização e o uso do outro como coisa. O mundo é duplo para o homem, pois ele vive entre estas dualidades em seu ser, o homem profere as palavras-princípios em sua vida de acordo com a relação que deseja estabelecer. É de sua inteira responsabilidade a escolha sobre a relação que irá ocorrer

[...] Não se pode falar em Eu sem mundo, sem Isso ou sem o Tu. Se o Eu decide-se por uma ou por outra atitude, significa que é o fenômeno da relação Homem-Mundo como um todo que define a possibilidade do Eu decidir. Do Eu depende a decisão, não de tomar uma atitude mas de tomar tal atitude, pois ele não é, senão quando decide tomar tal atitude diante do mundo. A iniciativa e o fundamento pertecem ao ser como $\mathrm{Tu}$. O Tu se oferece (não é procurado) ao encontro e o Eu decide encontrá-lo. Temos, então, o escolher e o ser escolhido, na mútua ação do face-a-face².

Apesar de todos os indivíduos possuírem a necessidade do diálogo, de uma relação verdadeira, é notável que os homens estejam gradativamente emergidos em seu próprio ego e sucumbindo ao mundo do Isso. E como essas palavras-princípios são inerentes aos homens e agem como duas consciências vivas dentro de seu ser, é necessário haver um equilíbrio entre elas para não desestabilizar a vivência do indivíduo. Em contrapartida, o que ocorre é precisamente tal desequilíbrio a favor do Isso sobre o $T u$, que constitui a mais prejudicial maneira de desequilíbrio. Por conseguinte, todo o processo de transição altera concomitantemente a mentalidade e as perspectivas dos homens, e na pós-modernidade3, este desnível está progressivamente pior em relação à modernidade.

Afinal, no século XX, houve profundas transformações na sociedade humana, a indústria e o capitalismo avançaram significativamente e ditavam o modo de vida econômico e social dos sujeitos. Dentre essas mudanças - reiterando em diversos setores econômicos e políticos - também ocorreram transformações no modo das relações interpessoais, pois é fato que os paradigmas de uma sociedade em um período de transições a afetam por inteiro em todas as suas instâncias. Por conta disso, estas questões sociais permanecem em discussões e reflexões devido a sua volátil transformação que acompanha tais mudanças paradigmáticas. Portanto, devido a tais alterações drásticas, ora ou outra os

\footnotetext{
${ }^{1}$ A terceira parte da obra discorre sobre o aspecto teológico do autor, onde a influência hassídica se dá de maneira mais explícita ao tratar sobre Deus e o chamado Tu eterno.

${ }^{2}$ VON ZUBEN, Eu e Tu, 37.

3 Pós-modernidade aqui, no sentido, de todas as mudanças provenientes na sociedade pós-guerra. Além de dialogar com a pós-modernidade de Bauman e as relações líquidas que o autor apresenta em suas obras.
} 
sujeitos e suas relações entram em desgaste afetivo, o que ocasiona algumas crises identitárias do sujeito, o qual procura "seu lugar no mundo".

Apesar de essa crise contemporânea estar edificada em nosso tempo, diversos estudiosos, principalmente inseridos como pertencentes à tradição da filosofia contemporânea, já haviam antevisto em séculos anteriores, um diagnóstico negativo sobre o futuro das relações interpessoais. Afinal, as relações humanas estão em crises há tempos. O individualismo exacerbado e a espetacularização das relações, por exemplo, foi o ponto em que filósofo Guy Debord (1931-1994) debruçou-se em sua obra A Sociedade do Espetáculo 4 (1967), que enunciava críticas ferozes à sociedade contemporânea, à sociedade do consumo, à relação que a sociedade apresentava em relação à cultura da imagem e o grande redemoinho em que o homem adentraria socialmente, tendo influência também, da situação política e econômica vigente.

Por conseguinte, o homem mais frágil socialmente é aquele cujas relações em sua maioria se dão de maneira objetivante, e é nesse homem que Buber e outros autores contemporâneos debruçaram-se, a fim de explicitar por meio de análises categóricas, como esse nível de impessoalidade edificou-se. Esse desamparo emocional é demasiadamente caro no cotidiano dos indivíduos, e no que tange às fragilidades humanas, um dos grandes estudiosos da atualidade foi Zygmunt Bauman (1925- 2017), o qual nos apresentou em suas obras, a perspectiva sobre o mundo líquido e as relações líquidas entre os homens. Bauman aponta em suas obras, como o contexto capitalista industrial afetou, progressivamente, a sociedade, e principalmente, as relações interpessoais. Assim, o homem passou a ter um medo de relacionar-se com seus semelhantes, pois isso gerava a possibilidade do desconhecido confrontada, causando desconfortos e sofrimentos, sem direitos a um escape 5 .

É importante frisar que há uma distinção entre uma relação autêntica verdadeira (Eu$\mathrm{Tu}$ ) com o outro, e relações esporádicas cujo objetivo é outros fins utilitários (Eu-Isso), que será detalhado mais adiante. Dessa forma, a atenção ao próximo que teoricamente teria de ser rotina, tornou-se algo estipulado com datas específicas e tempo definido, até mesmo, com a ânsia de este breve contato findar de vez. De fato, para Bauman, assim como para Buber, as relações necessitam de um resgate, da saída de um mundo líquido para uma relação sólida, estável, pois as relações definham diariamente, e com elas, definham também uma vivência saudável; a presença face a face tem que ser verdadeira e o diálogo de maneira autêntica, pois este é o $e u$-tu, o diálogo autêntico é o mais raro de ocorrer, logo, as relações necessitam de uma verdadeira autenticidade

Contudo, não basta uma relação qualquer, é preciso haver disponibilidade para relações autênticas, as quais não desvendem sobre aquilo que somos e com estamos, num revelar-se constante a experiência vivida, ao encontro na reciprocidade, o que nos permite nos reconhecer como pessoas. Quando não nos relacionamos, não somos reconhecidos; quando não somos reconhecidos, não existimos ${ }^{6}$.

O objetivo é compreender o quanto estamos nos desvinculando drasticamente das relações interpessoais e como a subjetividade está sendo alienada e subvertida pelo sistema

\footnotetext{
${ }^{4}$ A análise de Debord desperta diversas interpretações, mas nesse sentido deve-se notar que sua crítica estar inteiramente ligada ao mundo capitalista e suas reverberações na sociedade, sendo o espetáculo como esse conjunto que atravessa as relações sociais por meio das aparências que aliena os indivíduos devido à visibilidade da "vida perfeita" que estes outrora viam e viviam dentro do espetáculo. DEBORD, A Sociedade do Espetáculo, 23.

5 BAUMAN, A Arte da Vida, 29.

${ }^{6}$ PARREIRA, Martin Buber e o Sentido da Educação, 56.
} 
econômico da sociedade ocidental, o neoliberalismo, o qual modifica as raízes do modo de relacionarmos uns com os outros. Como dito inicialmente, os paradigmas do sistema econômico afetam diretamente o modo de vida dos sujeitos sociais, logo, se há uma profunda perda do sentimento de coletividade, solidariedade, e a corroboração de relações mercantilizadas, impessoais, desumanizadas entre os sujeitos, devemos nos atentar e investigar como se deu esse processo e sua implantação. A raiz do problema é discutir e compreender esses processos de transformação, que ocorrem etapa a etapa, ao ponto de que quando este processo já está estabelecido, é passível de surpresa por aqueles que não se deram conta das estratégias veladas para esse domínio, e assim encaram como algo espontâneo e avassalador.

\section{A vivência neoliberal dos indivíduos}

No que tange ao neoliberalismo, é necessário afirmar que não há pretensões de encerramento da discussão nesta pesquisa, pois seus aspectos estruturais são demasiadamente discutidos e refletidos pela comunidade científica, devido a sua volátil transição em seus âmbitos estruturais, econômicos, em suas formas de poder e controle, até mesmo, psicológico, além da difícil tarefa no que tange ao consenso acerca do que de fato é o neoliberalismo em uma descrição definitiva7. Dele emanam diversos ataques à esfera social e efeitos dramáticos na vivência dos sujeitos sociais, ressignificando sentimentos da individualização que já estavam presentes desde a modernidade de Bauman, por exemplo.

\footnotetext{
${ }^{7}$ Em nível de explanação abordaremos três perspectivas sobre o nascimento da teoria neoliberal a fim de provar como seus aspectos e tudo o que o diz respeito é rodeado de discussões devido a sua complexidade e volatilidade teórica e conceitual. Segundo BROWN, Nas Ruínas do Neoliberalismo a Ascensão da Política Antidemocrática no Ocidente, 28, "[...] o neoliberalismo não tem uma definição estabelecida. Existe atualmente uma literatura acadêmica substancial debatendo suas características construtivas. [...] o neoliberalismo - as ideias, as instituições, as políticas, a racionalidade política -, juntamente com sua cria, a financeirização, provavelmente moldaram a história mundial recente tão profundamente quanto qualquer outro fenômeno que possa ser situado no mesmo período, mesmo que acadêmicos continuem a debater o que ambos são precisamente. O termo 'neoliberalismo' foi cunhado no Colóquio Walter Lippman em 1938, uma reunião de acadêmicos que lançou as bases políticos-intelectuais daquilo que uma década depois se tornaria a Sociedade Mont Pélerin. O neoliberalismo é mais comumente associado a um conjunto de políticas que privatizam a propriedade e os serviços públicos, reduzem radicalmente o Estado social, amordaçam o trabalho, desregulam o capital e produzem um clima de impostos e tarifas amigável para investidores estrangeiros". Segundo LAVAL, DARDOT, A Nova Razão do Mundo Ensaio Sobre a Sociedade Neoliberal, 71, "A criação da Sociedade Mont Pélerin, em 1947, é citada com frequência, e erroneamente, como o registro de nascimento do neoliberalismo. Na realidade, o momento fundador do neoliberalismo situa-se antes, no Colóquio Walter Lippman, realizado durante cinco dias em Paris, a partir de 26 de agosto de 1938, no âmbito do Instituto Internacional de Cooperação Intelectual (antecessor da Unesco), na rue Montpensier, no centro de Paris. A reunião de Paris distingue-se pela qualidade de seus participantes, que, na maioria marcarão a história do pensamento e da política liberal dos países ocidentais após a guerra, quer se trate de Friedrich Hayek, Jacques Rueff, Raymond Aron, Wilhelm Ropke, quer se trate de Alexander von Rustow. Escolher uma dessas duas datas como momento fundador não é indiferente, como veremos adiante. A análise que se faz do neoliberalismo depende dessa escolha. Esses dois acontecimentos, aliás, estão correlacionados." E por último, Segundo HARVEY, $O$ Neoliberalismo História e Implicações, 29, "O neoliberalismo como potencial antídoto para ameaças à ordem social capitalista e como solução para as mazelas do capitalismo havia muito se achava oculto sob as asas da política pública. Um grupo pequeno e exclusivo de passionais defensores seus - principalmente economistas, historiadores e filósofos acadêmicos - se congregavam em torno do renomado filósofo político austríaco Friedrich von Hayek para criar a Mont Pelerin Society (que leva o nome do spa suíço em que se reuniram pela primeira vez) em 1947 (entre os notáveis estavam Ludwig von Mises, o economista Milton Friedman e mesmo, por algum tempo, o célebre filósofo Karl Popper). [...] a teoria neoliberal obteve respeitabilidade acadêmica quando Hayek em 1974 e Friedman em 1976 ganharam o prêmio Nobel de Economia”.
} 
Trata-se apenas de uma nova "roupagem" para mais um modo de controle sob a vida dos governados.

Exprimindo basicamente, o neoliberalismo é uma racionalidade que influencia o comportamento dos governados, ataca as instituições políticas como a democracia (de forma sútil), desmantela a justiça social, aprofunda as desigualdades, rege todas as políticas da sociedade e subverte as percepções de si e do outro. É uma era, sem dúvida, que apresenta novas relações e táticas entre o governo e os governados, onde cada sujeito comporta-se como uma empresa e o estado como uma instituição que defende interesses ocultos

[...] O neoliberalismo não destrói apenas regras, instituições, direitos. Ele também produz certos tipos de relações sociais, certas maneiras de viver, certas subjetividades. Em outras palavras, com o neoliberalismo, o que está em jogo é nada mais nada menos que a forma de nossa existência, isto é, a forma como somos levados a nos comportar, a nos relacionar com os outros e com nós mesmos. O neoliberalismo define certa norma de vida nas sociedades ocidentais e, para além-dela, em todas as sociedades que as seguem no caminho da "modernidade". Essa norma impõe a cada um de nós que vivamos num universo de competição generalizada, intima os assalariados e as populações a entrar em luta econômica uns contra os outros, ordena as relações sociais segundo o modelo do mercado, obriga a justificar desigualdades cada vez mais profundas, muda até o indivíduo, que é instado a conceber a si mesmo e a comportar-se como uma empresa. Há quase um terço de século, essa norma de vida rege as políticas públicas, comanda as relações econômicas mundiais, transforma a sociedade, remodela a subjetividade ${ }^{8}$.

O sujeito, agora inserido no sistema neoliberal, está cada vez mais vivendo apenas relações coisificadas, mercantilizadas, onde não ocorre o encontro atual entre homens baseados em mutualidade, ao contrário, o contato é instrumentalizado, programado, e em níveis que, de certa forma, ocorre de acordo como o sistema deseja que aconteça. $\mathrm{O}$ capitalismo subverteu os contatos entre os indivíduos de incontáveis maneiras e o sistema beneficiou-se disso e promoveu um maior distanciamento social ${ }^{9}$. As formas de manipulação foram intensificadas em nome do crescimento do capital, as demandas trabalhistas tornaram-se mais alienantes, estratégicas e letais aos trabalhadores. Assim, o sistema neoliberal possui uma estratégia quase irrefutável de manipular seus governados, dandolhes um sentimento de liberdade falsário ${ }^{10}$ que o aprisiona cada vez mais em seus interesses.

Dessa forma, a governamentalidade neoliberal transforma o estado em uma empresa "privada", que trabalha de forma estratégica para atender as demandas do mercado, e essa tática influencia diretamente a gestão pública, a qual passa a controlar mais ainda seus funcionários, suas autonomias, criando nele uma obsessão de controle com sua rotina de trabalho. Devido a isso, ocasiona em mais empenho por parte do trabalhador, que toma para si, devido às grandes pressões que sofre para obtenção de resultados, uma carga demasiada

\footnotetext{
${ }^{8}$ LAVAL, DARDOT. A Nova Razão do Mundo Ensaio Sobre a Sociedade Neoliberal, 14-15.

9 Distanciamento social aqui, no sentido, das relações pessoais em alteridade. Embora, de fato, cabe a menção das mudanças significativas de aproximação pelas redes sociais, conectando pessoas ao redor do mundo, e diminuindo fronteiras que antes eram impostas.

10 Essa liberdade pertence à lógica da teoria do liberalismo econômico clássico, que entre outras coisas, promete essa defesa do estado e garante a liberdade e posteriormente essa noção soma-se ao neoliberalismo, porém com ressalvas e problemas na prática.
} 
de trabalho para conseguir metas em nome da empresa e do capital, com a ideia subentendida de que seu esforço irá beneficiar a si mesmo e seu crescimento profissional

O objetivo dessa nova gestão pública é controlar estritamente os agentes públicos para aumentar seu comprometimento com o trabalho. Espera-se deles muito mais a obtenção de resultados (contabilizados como na empresa privada) do que o respeito aos procedimentos funcionais e ás regras jurídicas. [...] trata-se de reduzir a autonomia adquirida por alguns grupos profissionais, como médicos, juízes e professores, considerados dispendiosos, permissivos ou pouco produtivo, impondo-lhes critérios de resultado constituídos por uma tecnoestrutura especializada proliferante. Idealmente, cada indivíduo deve ser seu próprio supervisor, mantendo atualizadas a contabilidade de seus resultados e a adequação ás metas que lhe foram atribuídas. Um dos objetivos disso é fazer o indivíduo interiorizar as normas de desempenho e ás vezes, mais do que isso, fazer com que o avaliado seja o produtor das normas que servirão para julga-lo ${ }^{11}$.

Dessa forma, para obter constantes resultados dos indivíduos há um controle da empresa, a qual os pressiona constantemente a demonstração de uma capacitação obsessiva, tornando estes indivíduos reféns, pois o objetifica em seu cargo público, interiorizando problemas psicológicos no trabalhador devido à tamanha pressão profissional, pois quando o homem fracassa, se julga como único responsável, pois se vê como um empreendedor de si mesmo, seu próprio patrão cujo sucesso e fracasso dependem de si. Essa ferramenta de poder, da "empresa pessoal", é orientada com base no desejo do sujeito, implantada e reforçada pelo capitalismo

O capitalismo produz a massa. [...] o capitalismo e a sociedade burguesa privaram os indivíduos de comunicação direta e imediata uns com os outros, e eles foram constrangidos a só se comunicar por intermédio de um aparelho administrativo e centralizado. [Eles] reduziram portanto os indivíduos ao estado de átomos, de átomos submetidos a uma autoridade, a uma autoridade abstrata com o qual não se identificavam. A sociedade capitalista também sujeitou os indivíduos a um tipo de consumo maciço que tem funções de uniformização e de normalização. Enfim, essa economia burguesa e capitalista fadou os indivíduos a, no fundo, só se comunicar entre si pelo jogo dos signos e dos espetáculos ${ }^{12}$.

A prova dessa ferramenta de poder que torna refém o trabalhador, é o aumento na carga de trabalho mesmo durante a pandemia de Covid-19 que assola o mundo há meses, e transformou nossos hábitos e costumes, pois a sociedade teve que se reeducar à nova realidade devido à crise sanitária e a seguir as recomendações de isolamento social orientadas pela OMS (Organização Mundial da Saúde). Essa carga de trabalho passa a ser cumprida em casa durante o isolamento ${ }^{13}$, o chamado "Home Office", que tem se

\footnotetext{
${ }^{11}$ LAVAL, DARDOT. A Nova Razão do Mundo Ensaio Sobre a Sociedade Neoliberal, 304.

${ }^{12}$ FOUCAULT, Nascimento da Biopolítica, 88.

${ }^{13}$ Vale destacar que a pandemia revelou mais claramente as desigualdades sociais existentes no Brasil, no sentido de, por exemplo, o isolamento social recomendado pela OMS ser posto como prática ligada a uma parcela da população apenas, sendo colocada assim na posição de privilégio onde poucos usufruem, pois o "Home Office" não se aplica a todas as profissões existentes. Dessa maneira quem não pode cumprir o isolamento social tem de encarar o cotidiano da pandemia para trabalhar a fim de prover seu próprio sustento. Desigualdades estas, que o sistema neoliberal poderia apaziguar com medidas que garantiriam a segurança da população nessa crise sanitária, mas que não coloca em prática porque não está em seus interesses.
} 
popularizado durante esse período de suspensão de atividades presenciais e que diversos profissionais utilizam para cumprir suas respectivas atividades, por meio de plataformas que possibilitam reuniões on-line com certa quantidade de pessoas entre outras ferramentas tecnológicas. O que ocorre, é que tais cargas horárias de trabalho têm tomado um tempo muito significativo dos trabalhadores ${ }^{14}$, principalmente, servidores públicos, cujas jornadas de trabalho estão transpassando a carga horária normal estipulada pelas empresas nas atividades presenciais, não estabelecendo mais horários delimitados de trabalho ou os dias úteis de expediente. Além de ter que corresponder a atividades trabalhistas em um período de crise sanitária, vale salientar o esgotamento emocional e os problemas psicológicos que surgem devido à vivência em meio a uma pandemia que alastra, significativamente, o mundo com números exorbitantes no total de vidas perdidas para a doença. A racionalidade econômica do neoliberalismo aprisiona e esgota mais rapidamente o psicológico do indivíduo em meio à pandemia, o adoecendo e o exaurindo, devido a esse sistema que maximiza o mercado e a produção em detrimento do bem-estar dos indivíduos.

Por conseguinte, essas novas técnicas de manipulação e as novas amarras ao redor do indivíduo são para garantir a estabilidade dos interesses do capital, que coisifica as relações entre os homens, inserindo-os cada vez mais no mundo do Isso, de tal forma que a concorrência generalizada do sistema neoliberal não é natural, é formal, com uma lógica interna e sua própria estrutura, é produzida pela governamentalidade regularmente ativa do sistema. Assim, o capital aproveita-se da distração e competição uns com os outros para continuar se reproduzindo e subverte a liberdade individual em seu produto.

As explorações também ocorrem por meio de otimizações pessoais para controlar todos os aspectos sociais do indivíduo em nome do bom desempenho da jornada de trabalho, isso se dá, por exemplo, por meio de workshops, palestras motivacionais e etc. Assim, o homem transforma-se em um objeto pela técnica de dominação neoliberal, o coisifica. O regime neoliberal é dado pelo esgotamento da psique.

Dessa forma, a economia é como um jogo entre parceiros, e a sociedade é refém do jogo, ao mesmo tempo em que colabora para sua continuação.

Nesse sentido, é possível afirmar que o mundo do Isso preconizado por Buber tornouse vigente no contexto social dos indivíduos na era neoliberal, pois nesse cenário, observa-se que a coisificação, mercantilização das relações dar-se em nome do sucesso do capital que mantém seu sistema às custas de tais vivências, onde estes sujeitos são explorados, de diversos modos, e instigados a estabelecer relações monológicas, além de viver em ambientes permeados pela semente da competição, que também é legitimada e implantada pelo sistema neoliberal, aprofundando o individualismo contemporâneo sucumbindo em seu interior pelo mundo do Isso, resultando em vazio e desamparo. A sociedade neoliberal objetifica os sujeitos retirando sua humanidade, os transformando em meras "peças" para encaixar na roda do capital para o contínuo giro e obtenção de lucro, assim, desmantela o ser humano de maneira epistemológica, social, econômica e cultural, o subvertendo a um capital humano de interesses, que coopera (consciente e inconscientemente) a manter o sistema erguido.

Diante disso, é necessário ao indivíduo, livrar-se das amarras do individualismo, instigado e legitimado pelo sistema econômico, a fim de restabelecer a ética da alteridade e as relações autênticas da presença do $T u$, restabelecendo assim, o equilíbrio entre o mundo

\footnotetext{
${ }^{14}$ Como dito acima, as desigualdades sociais tornaram-se mais claras durante a pandemia (de modo que seria impossível elencar todas aqui) e a classe trabalhadora é a que mais tem sido prejudicada durante esse período, devido as suas más condições de trabalho em todos os setores, o que ocasiona que tais trabalhadores têm de se reinventarem constantemente para continuar exercendo suas jornadas e prover seu sustento, sem contar com a ajuda de seus empregadores ou do estado para reestabelecer boas condições de trabalho a classe.
} 
do Tu e do Isso, para uma vivência saudável. Isto, no entanto, não será de fácil resolução, pois o poder psicológico de controle na era neoliberal (assim como as outras táticas) é de natureza estratégica e até impiedosa, alienando o sujeito em sua essência e na percepção de si, transformando-o nesse capital humano e na "peça" de uma engrenagem para encaixe. Nesse sentido, deve-se então, permanecer em alerta e redirecionar o espírito de volta à alteridade e procurar a saída dentro deste poder do sistema e resistir à coisificação e desumanização vigente.

Se Martin Buber estivesse vivo para constatar a cruel realidade em que o indivíduo se encontra graças a um sistema econômico que tornou válido o mundo do Isso entre os sujeitos sociais, estaria petrificado e inconsolável pelo destino letal que a humanidade caminhou.

\section{Referências}

BAUMAN, Zygmunt. A Arte da Vida. Rio de Janeiro: Ed Zahar, 2009.

BUBER, Martin. Eu e Tu. Tradução do alemão, introdução e notas por Newton Aquiles Von Zuben. São Paulo: Centauro, 2001.

BUBER, Martin. Do Diálogo e do Dialógico. Tradução: Marta Ekstein de Souza Queiroz e Regina Weiberg; Produção e Revisão: Plinio Martins Filho. Posfácio Marcelo Dascal. Editora Perspectiva S.A, São Paulo - Brasil, 1982.

BROWN, Wendy. Nas ruínas do neoliberalismo a ascensão da política antidemocrática no ocidente. Traduzido por Mario A. Marino, Eduardo Altheman C. Santo. São Paulo: Editora Filosófica Politeia, 2019.

DARDOT, Pierre. LAVAL, Christian. A Nova Razão de Mundo Ensaio sobre a Sociedade Neoliberal. Ed Boitempo, Tradução de Mariana Echalar, Coleção Estado de Sítio, 2016.

DEBORD, Guy. A Sociedade do Espetáculo. Ed Contraponto editora, Brasil, 1997.

FOUCAULT, Michel. Nascimento da Biopolítica: curso dado no Collége de France (1978-1979). Edição estabelecida por Michel Senellart sob a direção de François Ewald e Alessandro Fontana. Tradução de Eduardo Brandão. Ed Martins Fontes, São Paulo: 2008 - (Coleção Tópicos).

GILES, Thomas Ranson. História do existencialismo e da fenomenologia. São Paulo: EPU, 1989.

HARVEY, David. O neoliberalismo história e implicações. Tradução de Adail Sobral e Maria Stela Gonçalves. Edições Loyola, São Paulo, Brasil, 2008.

PARREIRA, Gisele Geralda. Martin Buber e o Sentido da Educação. Goiania: IFG - 2016. 